\title{
Removal and Repositioning of a Piston Wire Prosthesis That Entered the Vestibule Secondary to Trauma in a Patient Who Underwent Stapedotomy
}

\author{
Sung Min Koh, Younghac Kim, Joo Hyun Park, and Young Sang Cho \\ Department of Otorhinolaryngology-Head and Neck Surgery, Samsung Medical Center, Sungkyunkwan University School of Medicine, \\ Seoul, Korea
}

Received October 29, 2021

Revised December 25, 2021

Accepted December 30, 2021

\section{Address for correspondence}

Young Sang Cho, MD

Department of Otorhinolaryngology-

Head \& Neck Surgery,

Samsung Medical Center,

Sungkyunkwan University

School of Medicine,

81 Irwon-ro, Gangnam-gu,

Seoul 06351, Korea

Tel $+82-2-3410-3579$

Fax +82-2-3410-3879

E-mail YS83.cho@samsung.com
Otosclerosis is a common cause of adult-onset hearing impairment, and stapedotomy is often performed as surgical treatment. Several studies have reported the complications of stapedotomy surgery; piston wire prosthesis (PWP) disruption or dislocation secondary to indirect force attributable to head trauma is described in many patients. Most PWPs that get displaced are slanted or are completely dislodged from the stapedotomy site and lodged within the middle ear. PWP dislocation into the vestibule is extremely rare. A 65-year-old woman who was involved in a traffic accident underwent computed tomography, which revealed a right-sided PWP in the vestibule. Two weeks after the accident, we observed conductive hearing loss associated with a large air-bone gap (ABG, $47 \mathrm{~dB}$ ) accompanied by spontaneous nystagmus directed to the right without any change in nystagmus following changes in head or body position. She underwent endoscopic exploratory tympanotomy under general anesthesia, 23 days after the injury. We gently pulled the PWP from the vestibule and repositioned it at its original site with a length of $5.2 \mathrm{~mm}$ on the long process of the incus. Pure tone audiometry performed 8 months postoperatively showed a decrease in the ABG from 47 to $10 \mathrm{~dB}$ without any complications.

J Audiol Otol 2022;26(4):223-226

Keywords: Hearing loss; Conductive; Endoscopic ear surgery; Stapes; Middle ear.

\section{Introduction}

Otosclerosis is the common cause of adult-onset hearing impairment. Otosclerosis is characterized by otic capsule bone remodeling that leads to progressive conductive hearing loss [1]. In a large European study of 236 temporal bones, the prevalence of otosclerosis was $2.5 \%$ [2]. In a similar study conducted in Japan, the prevalence of otosclerosis was $2.56 \%$ [3]. Though the etiology of the condition has been debated over several decades, it remains unclear.

The ultimate solution to otosclerosis is surgery. Since stapedotomy was introduced by Shea in 1956, the surgical technique has been greatly developed [4]. There have been many reports on the outcome of stapedotomy surgery. Reasons for

This is an Open Access article distributed under the terms of the Creative Commons Attribution Non-Commercial License (https://creativecommons.org/licenses/by-nc/4.0/) which permits unrestricted non-commercial use, distribution, and reproduction in any medium, provided the original work is properly cited. revision surgery include dislocated prosthesis, fibrous tractus, narrow stapedotomy, and crimping defect [5]. Also, indirect force resulting from head trauma disrupts or dislocates a piston wire prosthesis (PWP) [6]. Most PWPs that become displaced are either slanted or completely dislodged from the stapedotomy site and fall within the middle ear. In these cases, the operator can re-hang the PWP to the incus or, if the incus is broken, hang the PWP to the malleus. However, if the dislocated PWP enters the vestibule, it can cause severe damage to the saccule or utricle during removal, leading to dizziness or sensorineural hearing loss. Such cases are extremely uncommon. Here, we present a rare case of PWP dislocation into the vestibule and successful relocation without complications.

\section{Case Report}

A 65-year-old female underwent stapedotomy surgery on the right side due to otosclerosis at another hospital five years 
prior to this incident. The postoperative air-bone gap (ABG) decreased to within $20 \mathrm{~dB}$ and the patient had been without discomfort ever since. However, two weeks before she first visited our clinic, the patient was sitting in the backseat of a car without a seat belt. A rear collision accident occurred while the vehicle was stopped, and the patient slammed her forehead against the front seat headrest. She was alert but felt headache, back pain, severe vertigo, nausea, and right side hearing loss. She was taken to the nearest emergency room and brain computed tomography (CT) was performed. And there were no brain problems such as intracranial hemorrhage on the CT scan, but the right PWP was in the vestibule (Fig. 1). Although the vertigo was gradually disappeared, her hearing impairment did not change. So she consequently visit our ENT clinic for further examination and treatment.

At the first visit to the outpatient clinic, the patient complained of vertigo and right side hearing loss. On endoscopic ear examination, bilateral tympanic membrane and external auditory canal were normal. Fig. 2 is the result of her first pure tone audiometry (PTA) performed at our clinic. We observed severe conductive hearing loss with a large ABG $(47 \mathrm{~dB})$. In the physical examination to find the cause of the dizziness, there was spontaneous nystagmus directed to the right. And there was no nystagmus change caused by changes in head or body position.

After one week, the patient's dizziness somewhat improved and the nystagmus also decreased. But there was no possibility that the ABG in the right ear could recover spontaneously, so exploratory tympanotomy was performed using a $3 \mathrm{~mm} 0^{\circ}$ endoscope under general anesthesia 23 days after the trauma. When the tympanomeatal flap was carefully elevated, fracture was not observed in malleus and incus. However, out of the entire PWP, only the loop on the incus was barely exposed over the stapedotomy site. We used a right-angled pick to gently pull the PWP back from the vestibule. To prevent further damage to the vestibule, the PWP was removed by pulling

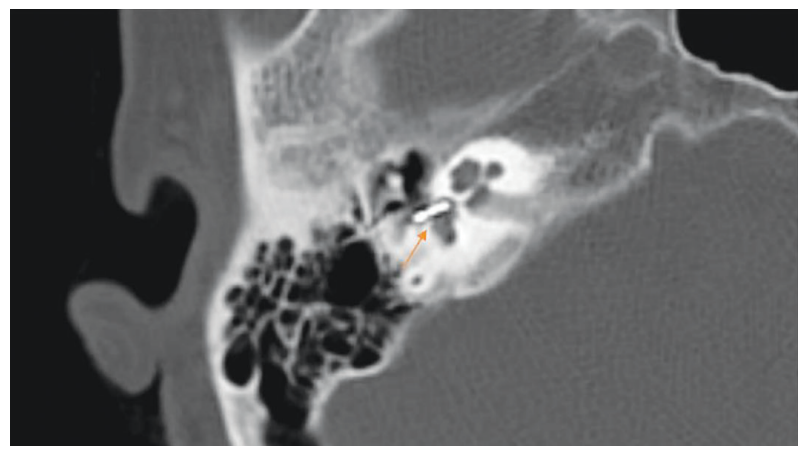

Fig. 1. Computed tomography image of the right temporal bone showing complete insertion of the piston wire prosthesis into the vestibule on the right side (arrow). very slowly under endoscopic investigation. After removal of the PWP, no perilymphatic fluid leakage was observed (Fig. 3). And we hang the PWP that it used to be with a length of $5.2 \mathrm{~mm}$ on the long process of incus. Then soft tissue and fibrin glue was packed on oval window.

PTA at eight months after surgery showed a decrease in ABG from 47 to $10 \mathrm{~dB}$ (Fig. 4). The patient did not feel dizzy, and no spontaneous or positional nystagmus was observed.

This case report was conducted retrospectively and was not subject to IRB. Written informed consent was obtained from the patient for publication of this case report and any accompanying images.

\section{Discussion}

The leading cause of revision stapes surgery is a dislocated prosthesis [5]. This is mainly caused by excessive fixation of prosthesis, resulting in pressure necrosis [7]. Extrusion of the prostheses by an external force has also been reported, but most dislocated prostheses are found within the middle ear cavity. There are several case reports that the footplate or prosthesis enter the vestibule after stapes surgery. Whetstone et al. [8] assessed 22 otosclerosis patients with failed stapes surgery and reported one case of intravestibular footplate dislocation. However, in this case, it was reported that the operation was not performed again because of sensorineural deafness [8]. And Sarac, et al. [9] also reported dislocation of stapes into the vestibule after trauma and repositioning of sta-

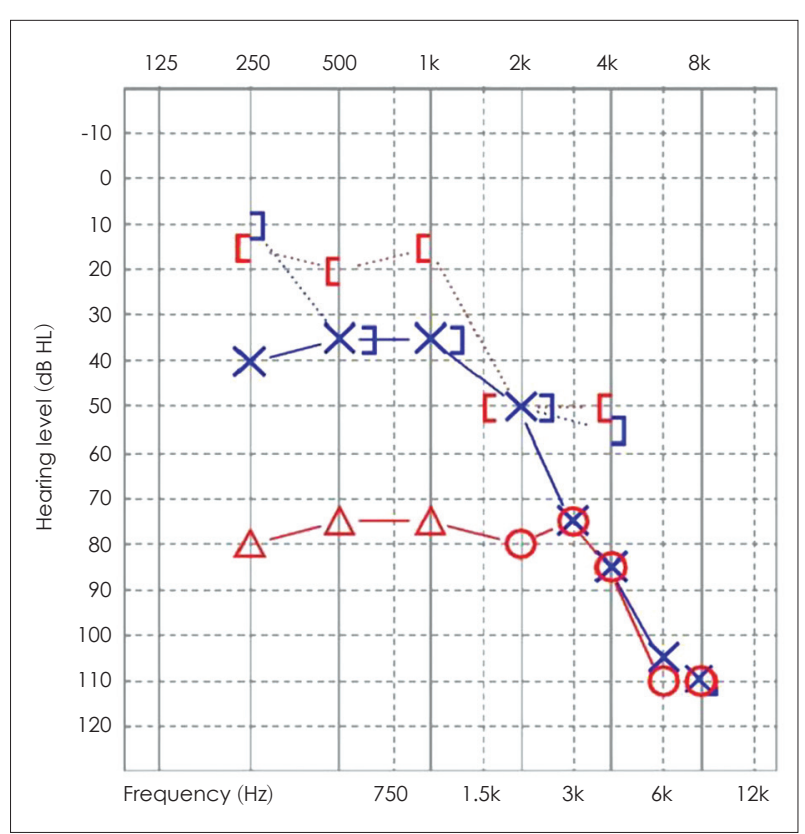

Fig. 2. Pure tone audiometry results: Hearing levels during the patient's first visit to our clinic. 

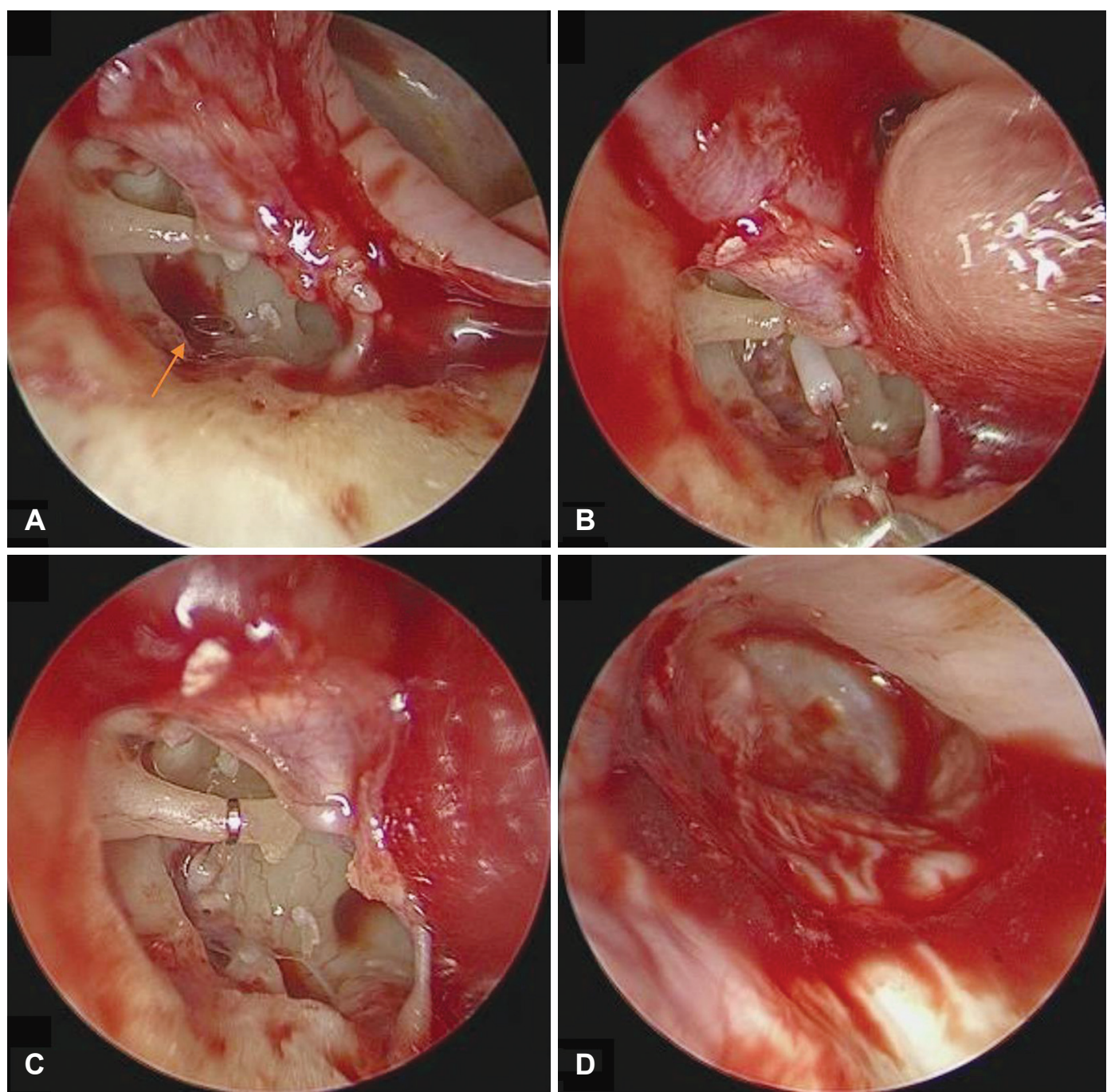

Fig 3. Endoscopic findings during surgery. A: The tip of the piston wire prosthesis (PWP) was observed around the oval window (arrow). $\mathrm{B}$ : The PWP was gently drawn back from the vestibule. C: Fixation of the PWP on the long process of the incus. D: Repositioning of the tympanic membrane.

pes, but there are no prior reports of PWP dislocation into the vestibule and removal and repositioning of PWP.

In our case, two mechanisms may have worked together: 1) a distorting force toward the vestibule occurred when the patient's head struck a hard, immovable structure and 2) the ossicular chain is mobile, but the PWP is relatively fixed, so the PWP slipped out of the long process of the incus and dislocated into the vestibule.

When vertigo, nystagmus, and hearing loss are presented stapes or prosthesis luxation should be suspected. To assess stapes or prosthesis luxation and even if it is in vestibule, highresolution computed tomography is imaging modality of choice [10].

When deciding whether the surgery is needed, the luxation degree of stapes or prosthesis is important. If the high-resolution computed tomography shows stapes or prosthesis is not deeply depressed in to the vestibule, good hearing can be expected after surgical remove [11,12]. However when it is deeply depressed, the risk of poor hearing loss is increased. Unfortunately when deeply depressed stapes or prosthesis is leaved to avoid hearing loss, late sensorineural hearing loss and vertigo due to scarring can be occur [13]. Thus we can remove luxated stapes or prosthesis right after diagnosis to avoid late onset hearing loss and vertigo due to scarring in inner ear.

In our case, an otolith function test such as vestibular evoked myogenic potential (VEMP) might be helpful, but the patient refused additional examination. And because there was no nystagmus directed to the opposite side, it could be expected that the vestibular function would be good. Therefore, we thought that the PWP would not show severe adhesion to the saccule or utricle and proceeded with exploratory tympanotomy. Very slow removal of the PWP from the vestibule while 


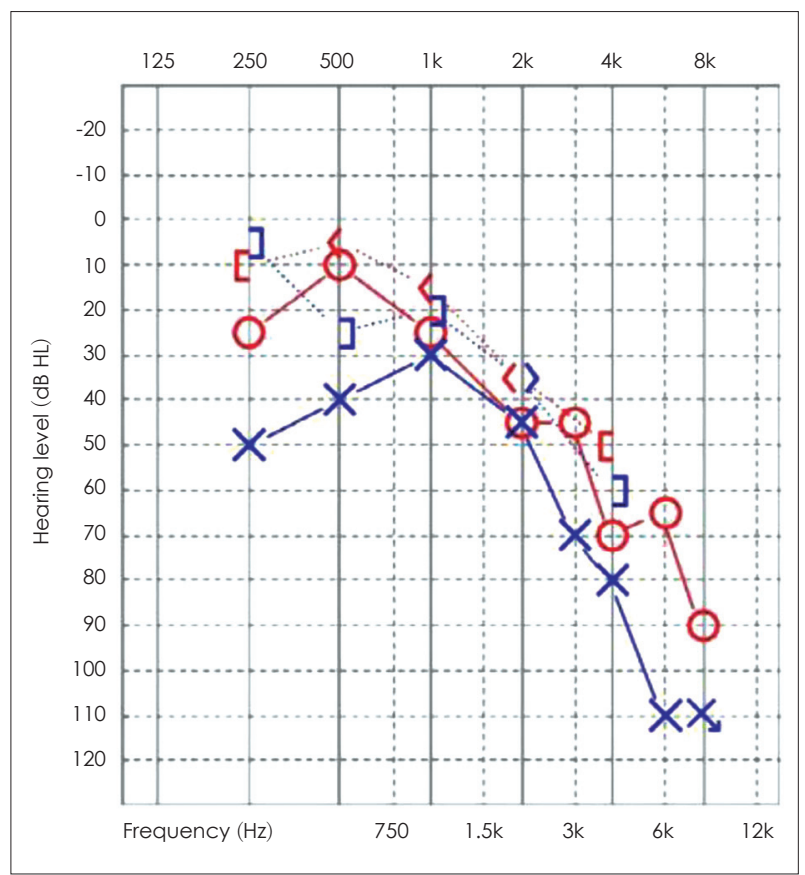

Fig. 4. Pure tone audiometry results: hearing levels at 2 months after the operation.

observing the PWP in a good field of view is the best course of action. We used a $3 \mathrm{~mm}$ endoscope for observation.

\section{Acknowledgments}

None

\section{Conflicts of interest}

The authors have no financial conflicts of interest.

\section{Author Contributions}

Conceptualization: Young Sang Cho. Investigation: Sung Min Koh. Project administration: Sung Min Koh. Resources: Younghac Kim, Joo Hyun Park. Supervision: Young Sang Cho. Writing — original draft: Sung Min Koh. Writing — review \& editing: Young Sang Cho. Approval of final manuscript: all authors.

\section{ORCID iDs}

Sung Min Koh

Younghac Kim

Joo Hyun Park

Young Sang Cho

https://orcid.org/0000-0003-3098-5229

https://orcid.org/0000-0002-3276-1408

https://orcid.org/0000-0001-7886-1917

https://orcid.org/0000-0002-4040-7206

\section{REFERENCES}

1) Crompton M, Cadge BA, Ziff JL, Mowat AJ, Nash R, Lavy JA, et al. The epidemiology of otosclerosis in a British cohort. Otol Neurotol 2019;40:22-30.

2) Declau F, Spaendonck MV, Timmermans JP, Michaels L, Liang J, Qiu JP, et al. Prevalence of histologic otosclerosis: an unbiased temporal bone study in Caucasians. Adv Otorhinolaryngol 2007;65:6-16.

3) Ohtani I, Baba Y, Suzuki T, Suzuki C, Kano M, Deka RC. Why is otosclerosis of low prevalence in Japanese? Otol Neurotol 2003;24:37781.

4) Marquet J, Creten WL, Van Camp KJ. Considerations about the surgical approach in stapedectomy. Acta Otolaryngol 1972;74:406-10.

5) Bakhos D, Lescanne E, Charretier C, Robier A. A review of 89 revision stapes surgeries for otosclerosis. Eur Ann Otorhinolaryngol Head Neck Dis 2010;127:177-82.

6) Hough JV, Stuart WD. Middle ear injuries in skull trauma. Laryngoscope 1968;78:899-937.

7) Rouhani MJ, Lavy J. Revision stapes surgery: a novel technique of overcoming erosion of the long process of incus using hydroxylapatite cement and shape memory piston. Otol Neurotol 2019;40:301-4.

8) Whetstone J, Nguyen A, Nguyen-Huynh A, Hamilton BE. Surgical and clinical confirmation of temporal bone CT findings in patients with otosclerosis with failed stapes surgery. AJNR Am J Neuroradiol 2014;35:1195-201.

9) Sarac S, Cengel S, Sennaroglu L. Pneumolabyrinth following traumatic luxation of the stapes into the vestibule. Int J Pediatr Otorhinolaryngol 2006;70:159-61.

10) Yamasoba T, Amagai N, Karino S. Traumatic luxation of the stapes into the vestibule. Otolaryngol Head Neck Surg 2003;129:287-90.

11) Arragg FG, Paparella MM. Traumatic fracture of the stapes. Laryngoscope 1964;74:1329-32.

12) Ogawa K, Kanzaki J, Ogawa S, Tsuchihashi N, Inoue Y, Yamamoto M. Traumatic perilymphatic fistulas by earpick. Otol Jpn 1994;4:18995.

13) Herman P, Guichard JP, Van den Abbeele T, Tan CT, Bensimon JL, Marianowski R, et al. Traumatic luxation of the stapes evidenced by high-resolution CT. AJNR Am J Neuroradiol 1996;17:1242-4 . 